\title{
Removal of benzaldehyde from a water/ethanol mixture by applying scavenging techniques
}

Mitic, Aleksandar; Skov, Thomas; Gernaey, Krist V.

\section{Published in:}

Green Processing and Synthesis

Link to article, DOI:

10.1515/gps-2016-0085

Publication date:

2017

Document Version

Publisher's PDF, also known as Version of record

Link back to DTU Orbit

Citation (APA):

Mitic, A., Skov, T., \& Gernaey, K. V. (2017). Removal of benzaldehyde from a water/ethanol mixture by applying scavenging techniques. Green Processing and Synthesis, 6(3), 353-361. https://doi.org/10.1515/gps-2016-0085

\section{General rights}

Copyright and moral rights for the publications made accessible in the public portal are retained by the authors and/or other copyright owners and it is a condition of accessing publications that users recognise and abide by the legal requirements associated with these rights.

- Users may download and print one copy of any publication from the public portal for the purpose of private study or research.

- You may not further distribute the material or use it for any profit-making activity or commercial gain

- You may freely distribute the URL identifying the publication in the public portal 


\section{Aleksandar Mitic, Thomas Skov and Krist V. Gernaey* Removal of benzaldehyde from a water/ethanol mixture by applying scavenging techniques}

DOI 10.1515/gps-2016-0085

Received April 30, 2016; accepted September 28, 2016; previously published online December 20, 2016

\begin{abstract}
A presence of carbonyl compounds is very common in the food industry. The nature of such compounds is to be reactive and thus many products involve aldehydes/ketones in their synthetic routes. By contrast, the high reactivity of carbonyl compounds could also lead to formation of undesired compounds, such as genotoxic impurities. It can therefore be important to remove carbonyl compounds by implementing suitable removal techniques, with the aim of protecting final product quality. This work is focused on benzaldehyde as a model component, studying its removal from a water/ethanol mixture by applying different derivatization agents as the scavengers. Discovery chemistry is performed in the beginning as a screening procedure, followed by the process design of a small-scale continuous process for benzaldehyde removal with in-line real-time monitoring. Applications of tris(hydroxymethyl)aminomethane (TRIS) are found to provide above average removal of benzaldehyde.
\end{abstract}

Keywords: carbonyl compounds; process analytical technology (PAT); process intensification; scavenger.

\section{Introduction}

High product quality is demanded in the modern food, chemical and biochemical industries. The achievement of this goal can be very challenging due to the potential presence of many undesired impurities. Good examples are genotoxic impurities (GTIs) that can easily contaminate final products. Such impurities are initiators of genetic mutation, chromosomal breaks or rearrangements, as well

\footnotetext{
*Corresponding author: Krist V. Gernaey, Department of Chemical and Biochemical Engineering, Technical University of Denmark (DTU), Søltofts Plads, Building 229, DK-2800 Kgs. Lyngby, Denmark, e-mail: kvg@kt.dtu.dk

Aleksandar Mitic: Department of Chemical and Biochemical Engineering, Technical University of Denmark (DTU), Søltofts Plads, Building 229, DK-2800 Kgs. Lyngby, Denmark

Thomas Skov: Department of Food Science, University of Copenhagen, Rolighedsvej 26, DK-1958 Frederiksberg, Denmark
}

as cancers in humans, and therefore have to be avoided in the final products [1-3].

Good precursors for the formation of GTIs are carbonyl compounds. The reactivity of aldehydes/ketones enables plenty of electrophilic and nucleophilic substitution reactions, such as synthesis of imines (semicarbazones, oximes and hydrazones), enamines, secondary amines, oxazolidines, unsaturated hydrocarbons through the Wittig reaction, and so on [4]. It is therefore crucial to detect carbonyl compounds early on, and then to perform their successful removal/scavenging.

Different chemical and physical approaches can be applied for scavenging aldehydes. Applications of adsorption techniques [5], such as usage of activated carbon [6, 7], alumina [8], and titanium [9] are very well-known already and have great applications in the petrochemical industry. The application of ex situ and in situ product removal technologies [10], such as pervaporation, has shown great advantages in fermentation processes [11]. Furthermore, an application of reactive extraction with amines has achieved great results with various aromatic and aliphatic carbonyl compounds [12]. Combinations of different technologies are also known in the removal of aldehydes from aqueous mixtures, such as combinations of adsorption and extraction technologies in the form of extractant impregnated resins [13]. Furthermore, solid-phase extraction in combination with derivatization techniques has shown great advantages due to the higher affinity of newly formed products towards adsorption [14, 15].

The main focus in this work is to remove benzaldehyde from a solvent mixture consisting of $70 \%$ water and $30 \%$ ethanol (volumetric ratio). The presence of benzaldehyde in the mentioned solvent mixture has a strong influence on the occurrence of side reactions, such as formations of hydrates, acetals and hemiacetals [4]. Its reactivity could additionally lead to formation of several GTIs, such as benzohydrazide, 1-benzoyl-2-[(4RS)-1-methylhexahydro-1-hazepin-4yl] diazane, aryl hydrazones, 4-hydrazine benzene sulfonamide, and so on [16].

It is important, for the above-mentioned reasons, to perform successful removal of benzaldehyde from the solvent mixture before any side reactions will occur. The screening procedure for obtaining a suitable scavenging technology for benzaldehyde was initially performed 
with amines [17-24], inorganic salts [25], organic acids and their anhydrides [19]. The most desired option was found to be tris(hydroxymethyl)aminomethane (TRIS), which converts carbonyl compounds into oxazolidines $[26,27]$. TRIS was used further in a process development study with the main aim to remove ppm levels of benzaldehyde. The initial process design was performed in batch mode with off-line high performance liquid chromatography (HPLC) analyses. A process intensification approach was implemented afterwards in order to move the process from batch to continuous processing [28]. Real-time process monitoring was also shifted towards in-line ultraviolet-visible (UV-VIS) spectroscopy in order to satisfy requirements defined in the frame of the process analytical technology (PAT) guidance [29]. Both types of processes are compared in order to evaluate advantages and disadvantages of the different operating modes. Future work will include process control studies and automation, as well as considerations of suitable scale up/out possibilities.

\section{Materials and methods}

\subsection{Materials and methods for off-line HPLC and UV-VIS analyses}

Off-line analyses of benzaldehyde during the initial screening procedure were performed by using an UltiMate 3000 HPLC device (Thermo Fisher Scientific, Boston, MA, USA). A suitable isocratic method was applied together with a Gemini-NX 3u C18 $110 \AA$ (100 mm $\times 2 \mathrm{~mm})$ column (Phenomenex Inc., Vaerloese, Denmark). The mobile phase, which consisted of $35 \%$ acetonitrile and $65 \%$ ultra-pure water with $\mathrm{NaOH}$ ( $\mathrm{pH}$ adjusted to be 11), was applied with a flow rate of $0.45 \mathrm{ml} /$ min. The oven temperature was adjusted to $30^{\circ} \mathrm{C}$ and the injection volume was fixed to $10 \mu \mathrm{l}$. It is furthermore important to add that the method lasted $5 \mathrm{~min}$ and that a wavelength of $244 \mathrm{~nm}$ was used for the UV detection. The retention time of benzaldehyde was $1.7 \mathrm{~min}$.

Analyses of benzaldehyde were additionally performed by using UV-VIS spectroscopy. To that purpose, a Shimadzu spectrophotometer UV-1800 (Shimadzu, Kyoto, Japan) was applied with the wavelength region between $200 \mathrm{~nm}$ and $400 \mathrm{~nm}$. Identification and quantification of benzaldehyde was performed by using a univariate method - absorbance at $249.80 \mathrm{~nm}$ was monitored in order to quantify the amounts of benzaldehyde.

\subsection{Materials and methods for the screening experiments}

Batch experiments were performed in the screening procedure. To that purpose, disposable $4 \mathrm{ml}$ glass vials were used as reactor vessels. They were sealed with polypropylene screw caps and placed in the HLC Biotech thermomixer (model MHR11; TG Instrument AB,
Helsinborg, Sweden). The thermomixer was equipped with a rack consisting of 16 places.

Applications of different derivatization agents were performed with the main aim to remove benzaldehyde from the solvent mixture consisting of $70 \%$ water and $30 \%$ ethanol (v/v). Constant reaction conditions were applied in all of the experimental runs. Hence, a reaction temperature of $50^{\circ} \mathrm{C}$ together with a $6 \mathrm{~h}$ (maximum) reaction time and a $1000 \mathrm{rpm}$ mixing speed were applied. The sampling procedure was based on taking samples every hour.

Disposable experimental equipment was purchased from VWR International (vials, septums and caps) whereas solvents and chemical catalysts were bought from Sigma-Aldrich.

\subsection{Materials and methods for the batch reactor experi- ments with on-line UV-VIS monitoring}

A schematic view of the setup is provided in Figure 4. Experimental work with a batch reactor was based on using a $50 \mathrm{ml}$ round bottom flask as the reactor vessel. It was placed on a magnetic stirrer that was used for regulating temperature and mixing in the reactor. The temperature was regulated with a water bath, whereas mixing was performed by using a common magnetic stirrer bar. The reactor had two inlets - one for TRIS dissolved in a water/ethanol mixture $(70 / 30 \mathrm{v} / \mathrm{v})$ and one for benzaldehyde that was dissolved in the same solvent. Stream 1 was pumped with the Watson Marlow pump (Wilmington, MA, USA) P1 from tank T1 to the batch reactor whereas the second stream was pumped with an additional Watson Marlow pump P2 from tank T2 to the same reactor. The reactor had also one outlet stream that was connected to the UV-VIS spectrophotometer via the flow cell type $C$. The flow cell was equipped with a special pump P3 that was used to suck the reaction mixture from the reactor and pump it into the cuvette. After performing the analyses, the reaction mixture was sent back from the cuvette to the reactor. For analyses, the kinetic method was applied (measuring just one wavelength over time). The same spectrophotometer as in section 2.1 was used.

\subsection{Materials and methods for the tubular laminar reactor experiments with in-line UV-VIS monitoring}

Experiments with a tubular laminar reactor were performed in a similar setup as for the batch experiments. A schematic view of the setup is depicted in Figure 6. The main part in this setup was a $5 \mathrm{~m}$ long laminar tubular reactor that was basically a PTFE tube with outer and inner diameters of $0.125 \mathrm{inch}(3.175 \mathrm{~mm})$ and $0.065 \mathrm{inch}$ $(1.65 \mathrm{~mm})$, respectively. The flow of TRIS dissolved in the water/ ethanol mixture (stream 1) was regulated by using a Watson Marlow pump (P1). Furthermore, an additional Watson Marlow pump (P2) was used for dosing the flow of benzaldehyde in the same solvent mixture (stream 2). Streams 1 and 2 were connected with a T-mixer before introducing both streams in the tubular laminar reactor. The reactor was placed in a silicon oil bath (R1) that was put on a magnetic stirrer. The main purpose of using a magnetic stirrer was to regulate the temperature in the reactor. The applied flow cell for the UV-VIS spectrophotometer was adapted for working under high pressure (a so-called "HPLC flow cell") and could go up to 30 bars. 


\section{Results and discussion}

\subsection{Screening procedure}

The screening procedure was focused on removing benzaldehyde from a $0.06 \mathrm{M}$ solution in a water/ethanol mixture $(70 / 30 \% \mathrm{v} / \mathrm{v})$. The first trial was focused on using n-butylamine and isatoic anhydride as scavengers, such as suggested by Sharma et al. [19]. The second attempt was based on testing a combination of ethanoic acid and ammonium acetate [25], whereas the third approach was using TRIS [26, 27]. The results achieved after $6 \mathrm{~h}$ of reaction time are depicted in Figure 1.

The best results were achieved if TRIS was applied as a scavenger. It can be seen in Figure 1 that around 55\% of benzaldehyde was scavenged after just $1 \mathrm{~h}$ of reaction time. The chemical reaction was performed for a total reaction time of up to $6 \mathrm{~h}$, but no significant changes were noticed after the first hour. Applications of the mixture "isatoic anhydride/n-butylamine" achieved a removal of approximately $45 \%$ of benzaldehyde after $6 \mathrm{~h}$ whereas the usage of the combination "ammonium acetate/ethanoic acid" resulted in a very low conversion of benzaldehyde - down to just $12 \%$ after $6 \mathrm{~h}$. It is important to emphasize that 3 eq. of TRIS were applied whereas a mixture of 1 eq. of isatoic anhydride and 1 eq. $n$-butylamine was applied in the "isatoic anhydride/n-butylamine" mixture [19]. Lastly, 10 eq. of ammonium acetate and 0.2 eq. of ethanoic acid were used in the "ammonium acetate/ethanoic acid" mixture [25].

\subsection{Further evaluation of TRIS}

The chemical reaction between TRIS and aldehydes leads to the formation of oxazolidines and water. According to the current knowledge, oxazolidines do not lead to GTIs, and are thus considered as harmless compounds. The particular example of the chemical reaction between TRIS and benzaldehyde is depicted in Figure 2 .

The screening procedure was focused on using 3 eq. of TRIS as a scavenger. An increase of the average conversions was performed by increasing the amount of TRIS in the reaction system. More precisely, 5 eq., 10 eq., 15 eq. and lastly 20 eq. were tested and the results are summarized in Figure 3. The increase in the ratio between TRIS and benzaldehyde resulted in significant improvements in the formation of oxazolidines. The results indicated an increase from $79 \%$ conversion of benzaldehyde when 5 eq. were used until almost $100 \%$ of conversion when 20 eq. of TRIS were used as a scavenger. The applied reaction conditions were the same as in the initial screening procedure $-1 \mathrm{~h}$ of reaction time and a temperature of $50^{\circ} \mathrm{C}$.

The high potential of TRIS in scavenging benzaldehyde was evaluated further in order to remove ppm levels of benzaldehyde from the water/ethanol solvent mixture. According to the chemical reaction depicted in Figure 2, it was easy to assume that higher amounts of TRIS would be needed in order to enable the chemical reaction to occur. Due to the double role of water - as a solvent and second product in the chemical reaction - the shift of the chemical equilibrium towards the formation of substrates

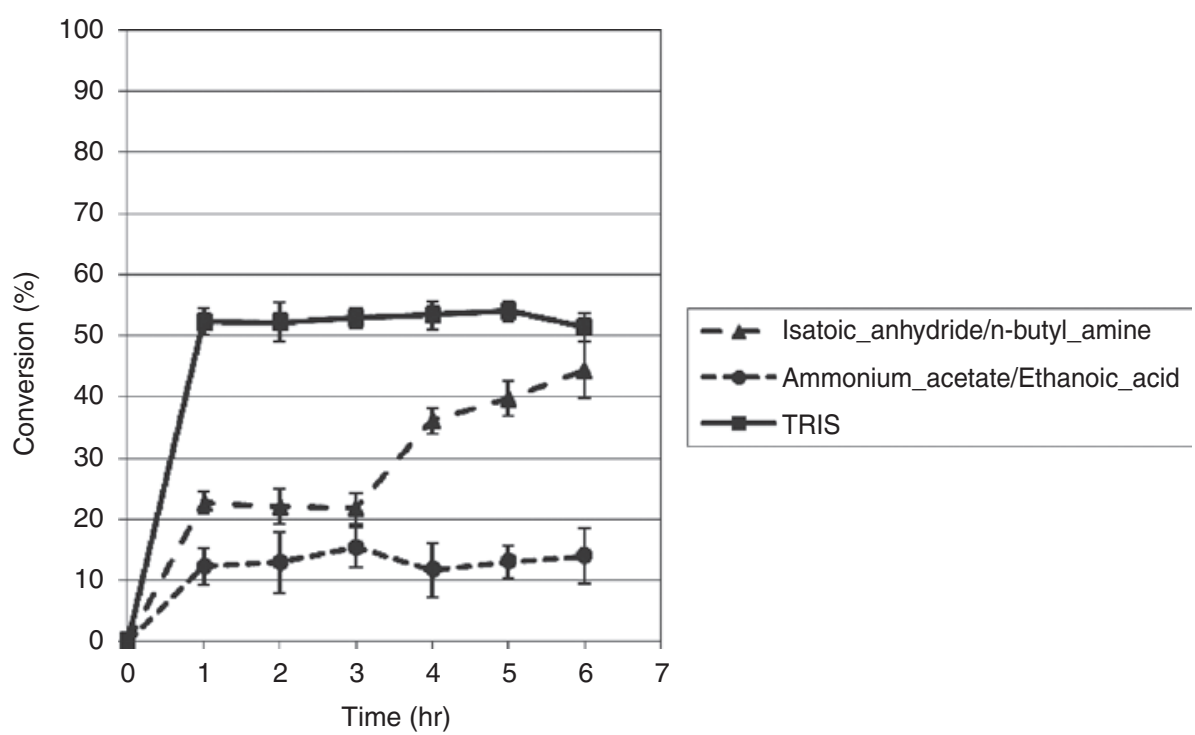

Figure 1: Scavenging of benzaldehyde from water/ethanol solvent mixture by applying different derivatization agents at $50^{\circ} \mathrm{C}$ and $1 \mathrm{~h}$ as the reaction time. 
<smiles>NC(CO)(CO)CO</smiles>

Figure 2: Chemical reaction between tris(hydroxymethyl)aminomethane (TRIS) and benzaldehyde [27].

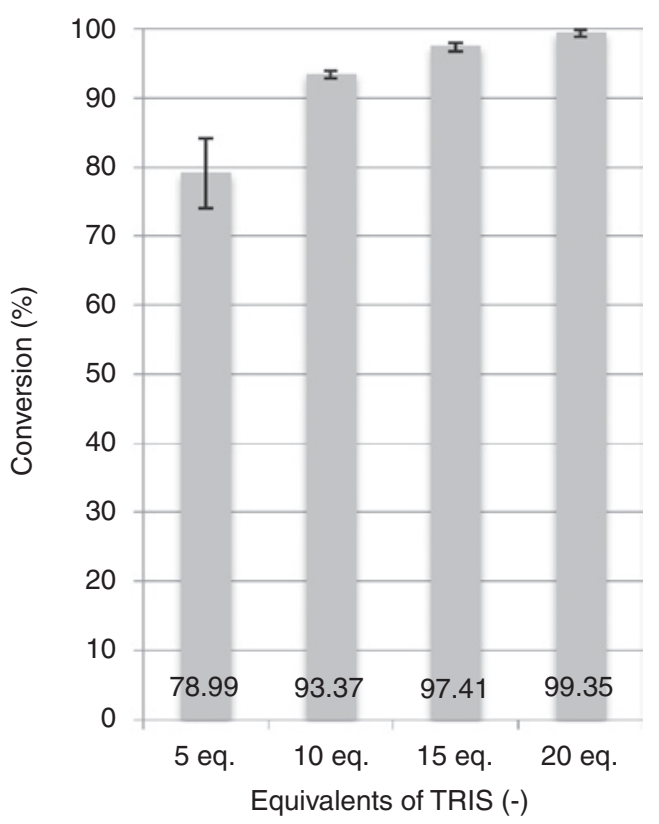

Figure 3: Removal of benzaldehyde from the water/ethanol solvent mixture when $0.06 \mathrm{M}$ solution of the aldehyde was treated with different amounts of tris(hydroxymethyl)aminomethane (TRIS) and after just $1 \mathrm{~h}$ of the reaction time for a temperature of $50^{\circ} \mathrm{C}$.

(benzaldehyde and TRIS) happened. Hence, it was necessary to use almost 0.6 M solutions of TRIS in order to decrease the concentration of benzaldehyde from $5 \mathrm{ppm}$ to approximately $1.5 \mathrm{ppm}$. The results depicted in Figure 4 describe the correlation between the conversion of benzaldehyde and the molar concentration of TRIS. The reaction conditions were the same as in the screening procedure $-1 \mathrm{~h}$ of reaction time and $50^{\circ} \mathrm{C}$.

\subsection{Batch reactor with on-line monitoring}

It was attempted to develop a deeper understanding of the chemical equilibrium established in the chemical reaction between amino alcohols and carbonyl compounds by investigating the reaction in a batch process with on-line real time process monitoring. To that purpose, an external loop with a UV-VIS flow cell and frequent sampling with

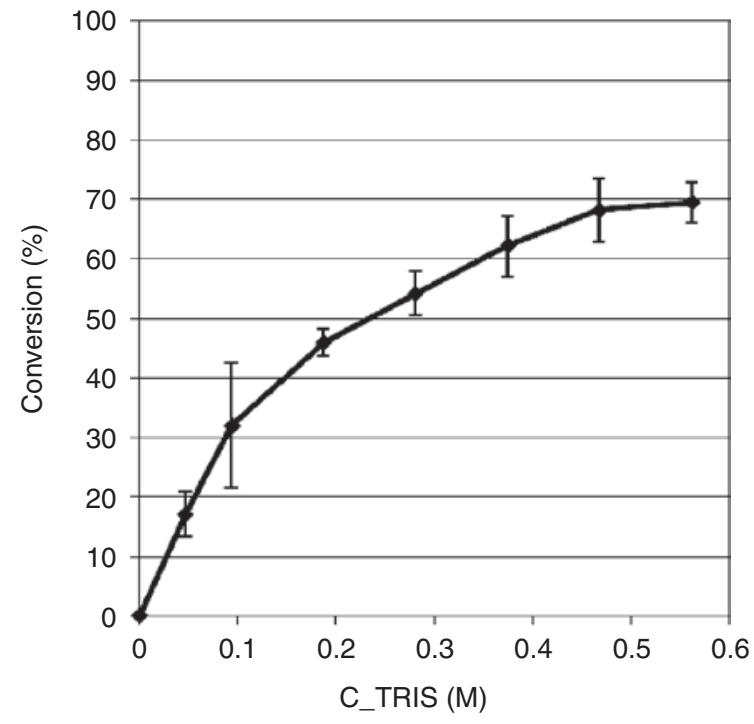

Figure 4: Removal of ppm levels of benzaldehyde (starting concentration $5 \mathrm{ppm}$ ) in the water/ethanol solvent mixture by using different molar concentrations of tris(hydroxymethyl)aminomethane (TRIS) as a scavenger and with a reaction time of $1 \mathrm{~h}$ at a temperature of $50^{\circ} \mathrm{C}$.

time intervals of 2.5 min was applied with the main goal to intensify our capability to observe kinetic phenomena. A schematic process flow scheme of this setup is depicted in Figure 5.

Three different temperatures were tested in the batch experimentation $\left(30^{\circ} \mathrm{C}, 40^{\circ} \mathrm{C}\right.$ and $\left.50^{\circ} \mathrm{C}\right)$ with a reaction time of $30 \mathrm{~min}$. The initial results are depicted in Figures $6 \mathrm{~A}-\mathrm{C}$ for reaction temperatures of $30^{\circ} \mathrm{C}, 40^{\circ} \mathrm{C}$ and $50^{\circ} \mathrm{C}$, respectively, and for different molar concentrations of TRIS (0.12 M, 0.23 M, 0.35 M, 0.47 M, 0.58 M, 0.70 M). It could be noticed that the highest benzaldehyde conversion was achieved if $0.70 \mathrm{M}$ of TRIS was used at the lowest reaction temperature $\left(30^{\circ} \mathrm{C}\right)$. A conversion of up to $82 \%$ of the benzaldehyde was achieved after approximately 20 min of reaction time under such conditions. It is furthermore important to note that additional reaction time was allowed in a few cases, but it did not affect the further conversion of benzaldehyde.

A temperature increase causes a faster establishment of the equilibrium, which is clearly depicted in Figure 6. However, at the same time the temperature increase results in lower conversions of benzaldehyde into oxazolidine. More precisely, by using $0.70 \mathrm{M}$ of TRIS, the equilibrium was achieved after $20 \mathrm{~min}$ at $30^{\circ} \mathrm{C}$, then after $15 \mathrm{~min}$ at $40^{\circ} \mathrm{C}$ and just after $10 \mathrm{~min}$ at $50^{\circ} \mathrm{C}$. The conversions simultaneously decreased from $82 \%$ at $30^{\circ} \mathrm{C}$ to $78 \%$ and $73.3 \%$ at $40^{\circ} \mathrm{C}$ and $50^{\circ} \mathrm{C}$, respectively. It is therefore important to emphasize that a temperature increase leads to a faster establishment of the reaction equilibrium, which 


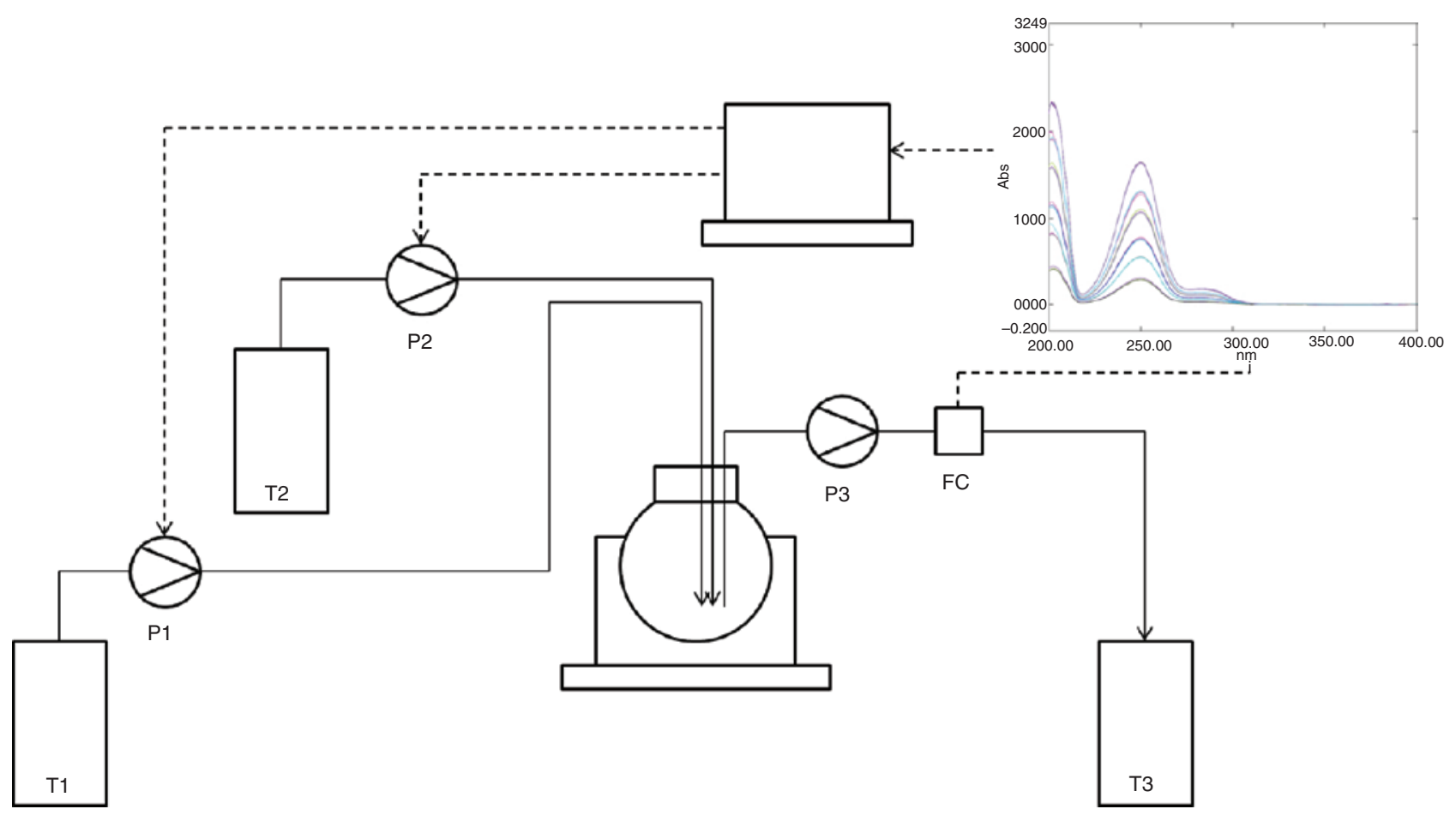

Figure 5: Experimental setup for performing the chemical reaction between tris(hydroxymethyl)aminomethane (TRIS) and benzaldehyde in a batch reactor with on-line ultraviolet-visible (UV-VIS) real time process monitoring. Process flow sheet including: T1, T2, T3 - storage tanks; P1, P2 and P3 - pumps; T - thermometer, FC - flow cell. See text for an explanation of the operation of the setup.

could potentially decrease reaction time, but comes at the cost of a lower overall conversion.

The amount of benzaldehyde that is scavenged from the water/ethanol mixture decreased by almost $10 \%$ by increasing the temperature by $20^{\circ} \mathrm{C}$, and therefore it can be expected that a further temperature increase could lead to a further decrease of the removed amount of benzaldehyde. Nevertheless, as a result of the batch experiments, it could be confirmed for all reaction conditions tested that a final water/ethanol solvent mixture containing less than $1.5 \mathrm{ppm}$ of benzaldehyde was obtained, compared to an initial benzaldehyde concentration of $5 \mathrm{ppm}$.

From a practical point of view, a decrease of the benzaldehyde concentration from $5 \mathrm{ppm}$ down to approximately $1 \mathrm{ppm}$ is a very high accomplishment. Even small amounts of carbonyl compounds have a significant influence on the formation of GTIs, and therefore a decrease of approximately $80 \%$ of the benzaldehyde present in the solvent mixture diminishes the possibilities for synthesis of such undesired impurities. Adaptation of the reaction conditions, such as temperature and reaction time, is dependent on the final goals of a particular application. Hence, if higher amounts of carbonyl compounds should be removed, it is probably important to use lower temperatures and higher reaction times. By contrast, if it is important to perform quick removal of aldehydes/ketones, the approach with higher temperatures and lower reaction times is more desired.

Application of TRIS in the removal of benzaldehyde has additional benefits. It is firstly important to note that the high reactivity of TRIS opens up a possibility to scavenge other carbonyl compounds, as well as esters and also several additional impurities. Products of the chemical reactions between TRIS and aldehydes/ketones, so called oxazolidines, are harmless at ppm levels. Until now, nothing has indeed been registered in the literature about the harmful effects of such compounds present in such concentration levels. TRIS is additionally widely used in the biotechnological industry due to its versatility in organic chemistry. Applications of such a compound are also economically justified. It is used widely for preparing buffer solutions in the biotechnological industry, and therefore it is a well-known reagent, meaning that its price and treatment costs are relatively affordable. More importantly, when adopting a scavenging approach with TRIS, as presented here in a production environment, this would also mean that industry can avoid the introduction of a new chemical compound, thereby minimizing the amount of experimental work and validation that would be required for documentation. 
A

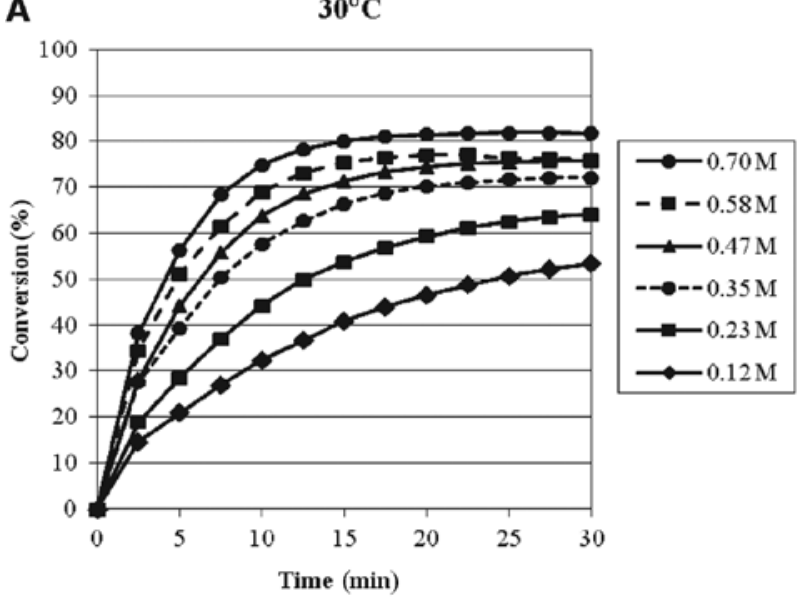

B

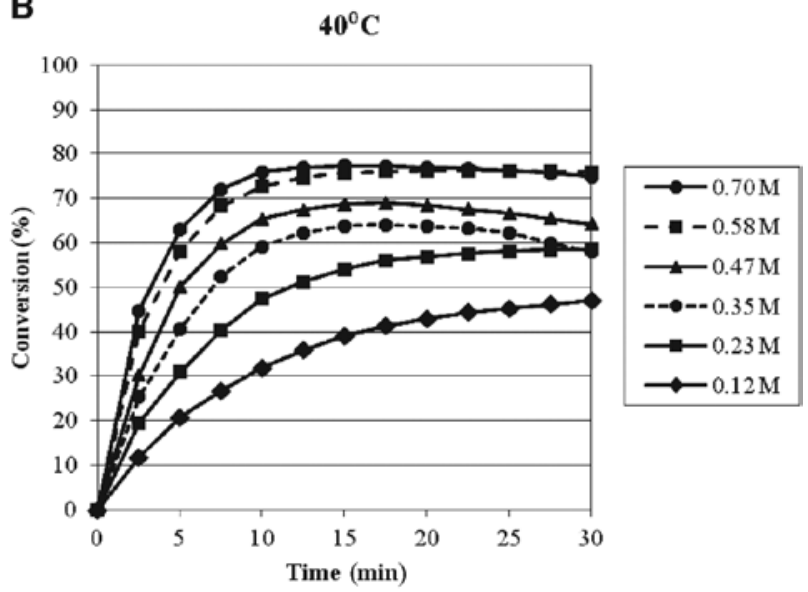

C

$50^{\circ} \mathrm{C}$

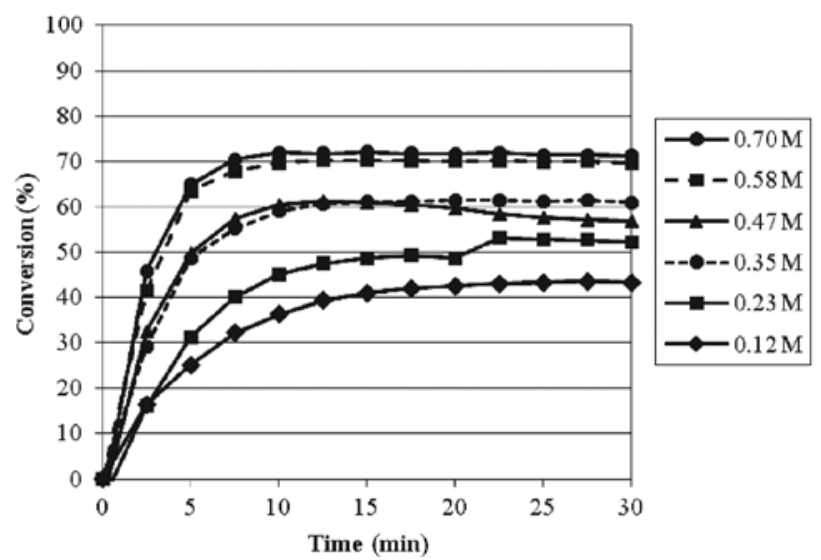

Figure 6: Batch experiment results for removal of $5 \mathrm{ppm}$ of benzaldehyde when tris(hydroxymethyl)aminomethane (TRIS) is applied as a scavenger in a water/ethanol mixture $(70 \% / 30 \% \mathrm{v} / \mathrm{v})$ performed with six different concentrations of TRIS $(0.12 \mathrm{M}, 0.23 \mathrm{M}, 0.35 \mathrm{M}, 0.47 \mathrm{M}$, $0.58 \mathrm{M}, 0.7 \mathrm{M}$ ) and at three different temperatures (A) $30^{\circ} \mathrm{C}$, (B) $40^{\circ} \mathrm{C}$ and $(\mathrm{C}) 50^{\circ} \mathrm{C}$. Standard deviations are below $1 \%$ and excluded from the graphs.

\subsection{Continuous tubular laminar reactor with in-line monitoring}

An implementation of the process intensification approach is focused on developing processes that operate in continuous mode [28]. A laminar tubular reactor was therefore designed with in-line UV-VIS real-time process monitoring. A few of the PAT demands are satisfied in this way, by allowing faster data acquisition and thus opening up for achieving a better process understanding. The process flow scheme is depicted in Figure 7.

The selected molar concentrations of TRIS for the experiments in continuous mode were decided on the basis of the best performances achieved in the batch reactor. Hence, $0.7 \mathrm{M}$ TRIS in a water ethanol mixture was used in the laminar tubular reactor. The results for three different temperatures $\left(30^{\circ} \mathrm{C}, 40^{\circ} \mathrm{C}\right.$ and $\left.50^{\circ} \mathrm{C}\right)$ and for a
10 min reaction time are depicted in Figure 8. A flow rate of $1 \mathrm{ml} / \mathrm{min}$ was applied.

Similar to the batch experiment, it can be seen that the best performance is again reached at a temperature of $30^{\circ} \mathrm{C}$ with $82.5 \%$ conversion of benzaldehyde, whereas the increase in temperature to $40^{\circ} \mathrm{C}$ resulted in $80.9 \%$ conversion. The last tested temperature was $50^{\circ} \mathrm{C}$ and as expected from batch experiment results - the lowest conversion of benzaldehyde was achieved, which was around $78 \%$.

The obtained results in continuous mode were compared to the removal of benzaldehyde achieved in the batch mode for the following residence times: $2.5 \mathrm{~min}$, $5 \mathrm{~min}$ and $10 \mathrm{~min}$. The residence times correspond to the following flow rates in the tubular laminar reactor: $4 \mathrm{ml} /$ $\mathrm{min}, 2.5 \mathrm{ml} / \mathrm{min}$ and $1 \mathrm{ml} / \mathrm{min}$, respectively. The results of this comparison are depicted in Figure 9. 


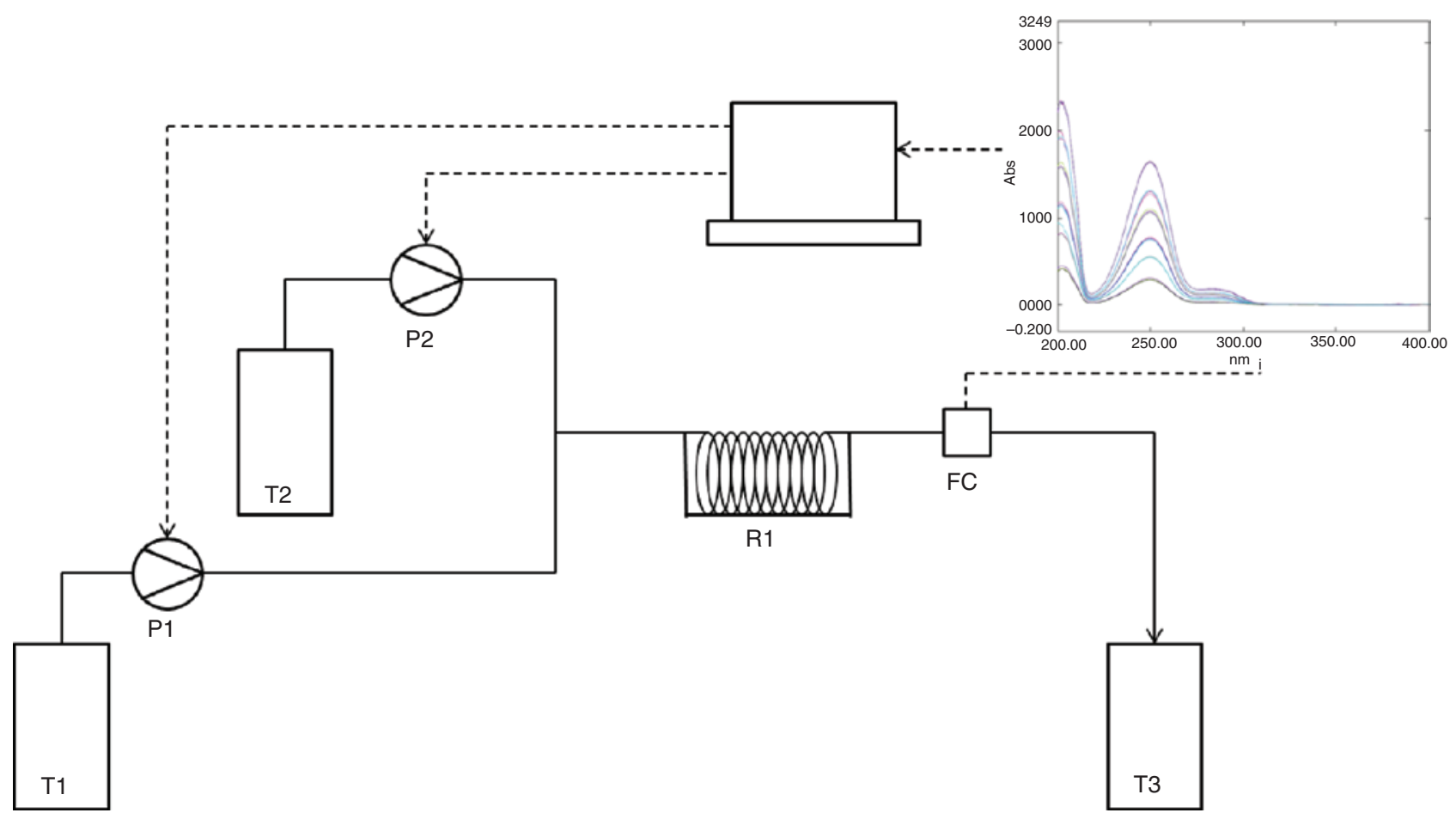

Figure 7: Experimental setup for performing the chemical reaction between tris(hydroxymethyl)aminomethane (TRIS) and benzaldehyde in a tubular laminar reactor with in-line ultraviolet-visible (UV-VIS) real time process monitoring. Process flow sheet including: T1, T2, T3 tanks; P1 and P2 - pumps; T - thermometer, FC - flow cell and R1 - tubular laminar reactor.

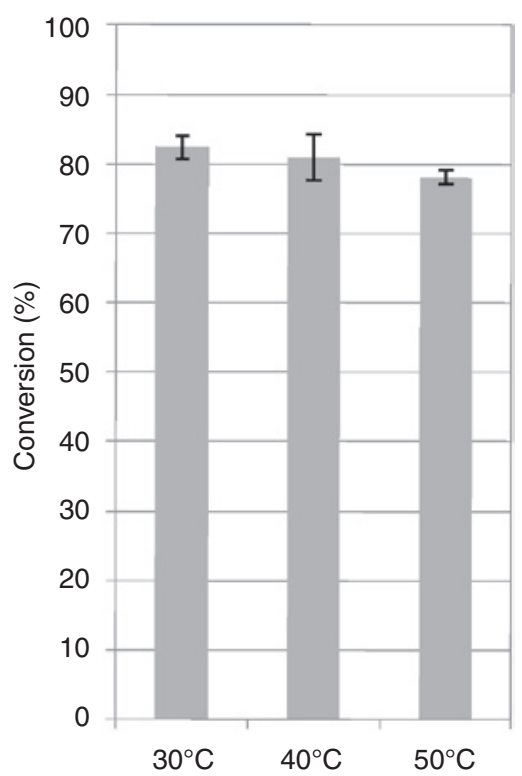

Figure 8: Conversion of benzaldehyde at $30^{\circ} \mathrm{C}, 40^{\circ} \mathrm{C}$ and $50^{\circ} \mathrm{C}$ in a tubular laminar reactor by applying a $0.7 \mathrm{M}$ solution of tris(hydroxymethyl)aminomethane (TRIS) as a scavenger and for a 10 min reaction time.

A conversion of almost $82.5 \%$ was achieved very quickly in a tubular reactor, which was $8 \%$ higher compared to the batch reactor performance. Such differences are most probably associated with the physical phenomena that are more dominant in meso-scale devices such as better mass/heat transfer, as well as better mixing and higher surface to volume ratios.

\section{Conclusions and future perspectives}

The screening procedure demonstrated that TRIS is the most versatile scavenger for removing aromatic carbonyl compounds. A higher molar concentration of benzaldehyde is easily scavenged from the water/ethanol solvent mixture $(70 \% / 30 \% \mathrm{v} / \mathrm{v})$, whereas ppm levels of benzaldehyde demanded a significant increase of the amount of TRIS used. The main reason for such behavior is associated with the established reaction equilibrium between TRIS and benzaldehyde on the one side and the newly formed oxazolidine and water on the product side. Hence, a $0.7 \mathrm{M}$ solution of TRIS was needed in order to perform a decrease of the concentration of benzaldehyde from $5 \mathrm{ppm}$ down to $1.5 \mathrm{ppm}$

Successful lab-scale process designs in batch and continuous modes were established with on- and in-line real-time monitoring, respectively. It was noticed that a 


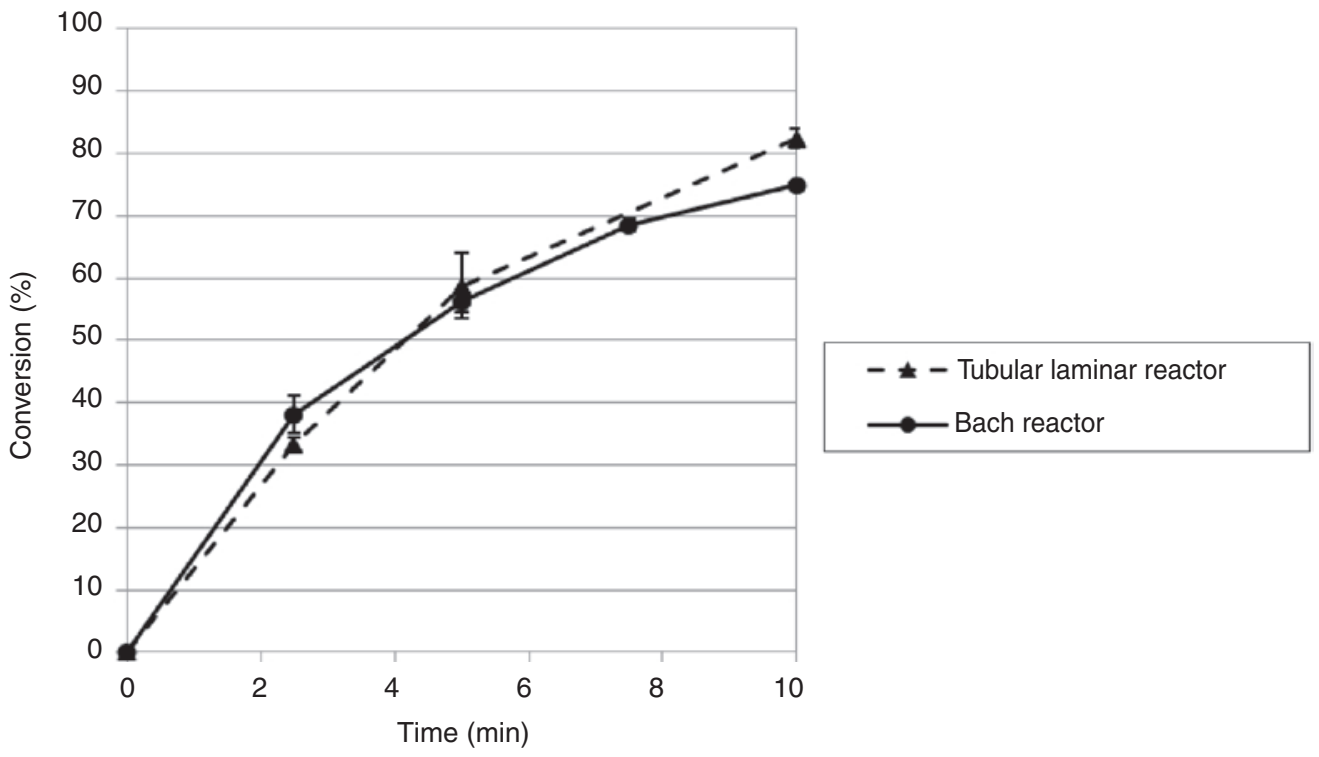

Figure 9: Comparison between performances of tubular laminar and batch reactors at $30^{\circ} \mathrm{C}$ by applying $0.7 \mathrm{M}$ of tris(hydroxymethyl)aminomethane (TRIS) as a scavenger and for a 10 min reaction time.

chemical equilibrium was established faster when the temperature was increased from $30^{\circ} \mathrm{C}$ to $50^{\circ} \mathrm{C}$, however, the overall conversion of benzaldehyde decreased with the increase of temperature. It is additionally important to note that a better performance was observed if a tubular laminar reactor operated in continuous mode was used as a reactor vessel instead of a batch vessel, which can most probably be attributed to the better mass/heat transfer, mixing and surface to volume ratios.

The further work is focused on establishing immediate analyses of the data collected by in-line process monitoring and UV-VIS spectroscopy, by applying a multivariate calibration) model. In this way, process automation with feedback process control can be established.

Acknowledgments: The authors would like to acknowledge the Technical University of Denmark (DTU), Copenhagen University (KU) and BIOPRO2. The project received financial support from Innovation Fund Denmark through the BIOPRO2 strategic research center (grant no. 4105-00020B).

\section{References}

[1] Bouder F. Expert Rev. Clin. Pharmacol. 2008, 1, 241-250.

[2] Müller L, Mauthe RJ, Riley CM, Andino MM, Antonis DDe, Beels C, DeGeorge J, De Knaep AGM, Ellison D, Fagerland JA, Frank R, Fritschel B, Galloway S, Harpur E, Humfrey CDN, Jacks AS, Jagota N, Mackinnon J, Mohan G, Ness DK, O’Donovan MR,
Smith MD, Vudathala G, Yotti L. Regul. Toxicol. Pharmacol. 2006, 44, 198-211.

[3] Bolt HM, Foth H, Hengstler JG, Degen GH. Toxicol. Lett. 2004, 151, 29-41.

[4] Clayden J, Warren W, Greeves N, Eds., Organic Chemistry, 2nd ed., Oxford University Press: Oxford, 2012.

[5] Kecili R, Nivhede D, Billing J, Leeman M, Sellergren B, Yilmaz E. Org. Process Res. Dev. 2012, 16, 1225-1229.

[6] Giusti DM, Conway RA, Lawson CT. J. Water Pollut. Control Fed. 1974, 46, 947-965.

[7] Rajoriya RK, Prasad B, Mishra IM, Wasewar KL. Chem. Biochem. Eng. 2007, 21, 219-226.

[8] Kuiper AET, Medema J, Van Bokhoven JJGM. J. Catal. 1973, 29, 40-48.

[9] Idriss H, Pierce KG, Barteau MA, Science C. J. Am. Chem. SOC 1994, 116, 3063-3074.

[10] Heintz S, Mitic A, Ringborg RH, Krühne U, Woodley JM, Gernaey KV. J. Flow Chem. 2016, 6, 18-26.

[11] Lamer T, Spinnler HE, Souchon I, Voilley A. Process Biochem. 1996, 31, 533.

[12] Babic K, Van der Ham AGJ, De Haan A. Sep. Purif. Technol. 2009, 66, 525-531.

[13] Babic K, Van der Ham L, De Haan, A. React. Funct. Polym. 2006, 66, 1494-1505.

[14] Baños CE, Silva M. Talanta 2009, 77, 1597-1602.

[15] Fernández-Molina JM, Silva M. Talanta 2011, 85, 449-454.

[16] Jouyban, A, Parsa, H. In Toxicity and Drug Testing, William A, Eds., INTECH Open Access Publisher: Rijeka, Croatia, 2012, p 387.

[17] Kemal Ö, Reese CB. J. Chem. Soc. Perkin Trans. 1981, 1, 1569-1573.

[18] Katritzky AR, Laurenzo KS. J. Org. Chem. 1988, 53, 3978-3982.

[19] Sharma R, Pandey AK, Chauhan PMS. Synlett 2012, 23, 2209-2214.

[20] Mandhane, PG, Joshi RS, Nagargoje DR, Gill CH. Chin. Chem. Lett. 2011, 22, 563-566. 
[21] Li JT, Li YW, Song YL. Synth. Commun. 2012, 42, 2161-2170.

[22] Voziyan PA, Metz TO, Baynes JW, Hudson BG. J. Biol. Chem. 2002, 277, 3397-3403.

[23] Thornalley PJ, Yurek-George A, Argirov OK. Biochem. Pharmacol. 2000, 60, 55-65.

[24] Bird SD, Legge M, Walker RJ. Nephrology 2004, 9, 65-72.

[25] Wolkenberg SE, Wisnoski DD, Leister WH, Wang Y, Zhao Z, Lindsley CW. Org. Lett. 2004, 6, 1453-1456.

[26] Trivic S, Leskovac V, Zeremski J, Stancic B, Anderson BM. J. Enzyme Inhib. 1998, 13, 57-68.

[27] Bubb WA, Berthon HA, Kuchel PW. Bioorg. Chem. 1995, 23, 119-130.

[28] Mitic A, Gernaey KV. Chem. Eng. Technol. 2015, 38, 1699-1712.

[29] Mitic A, Heintz S, Ringborg RH, Bodla V, Woodley JM, Gernaey KV. Chem. Today 2013, 31, 4-8.

\section{Bionotes}

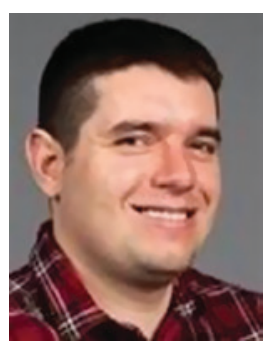

\section{Aleksandar Mitic}

Aleksandar Mitic is a postdoc in the CAPEC-PROCESS Research Center at the Technical University of Denmark (DTU). His main research focus is on designing and improving processes by applying tools/techniques related to the Process Systems Engineering, Quality by Design, Process Analytical Technology (PAT) and Lean Production System disciplines, as well as organic/inorganic chemistry. Aleksandar received his PhD degree from DTU Chemical Engineering in 2014 in the field of process intensification of pharmaceutical production processes whereas his Dipl.-Ing. degree was received in 2010 from the University of Novi Sad (Faculty of Technology, Department of Oil-Petrochemical Engineering, Serbia).

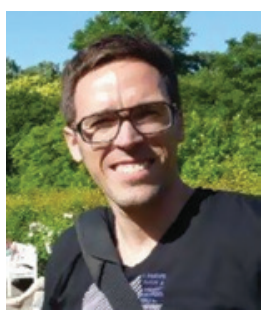

Thomas Skov

Thomas Skov is an associate professor in biotechnology and chemometrics at the Department of Food Science, University of Copenhagen. He obtained his PhD degree from the University of Copenhagen (2008) in the area of multivariate data analyses (chemometrics), whereas his Master's degree was obtained from The Royal Veterinary and Agricultural University (2003). His main research focus is on biotechnological optimization, PAT and development of soft sensors. Thomas Skov has co-authored around 60 publications in peer reviewed journals.

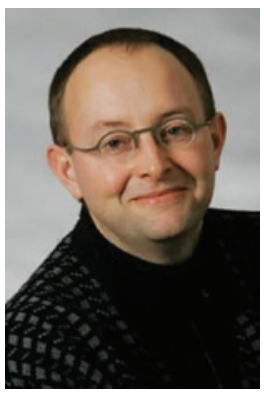

Krist V. Gernaey

Krist V. Gernaey has a Master's degree (1993) and PhD degree (1997) from Ghent University (Belgium). He is a professor in industrial fermentation technology and head of the CAPEC-PROCESS Research Center, Department of Chemical and Biochemical Engineering, DTU. His main research focus is on the development and optimization of fermentation, biocatalysis, pharmaceutical and biological wastewater treatment processes. His research work also includes mathematical modeling, investigation of mass transfer in bioreactors, scale-up and scale-down of bioreactors, PAT and development of continuous production processes. Krist V. Gernaey has until now co-authored 172 publications in peer reviewed journals ( $\mathrm{H}$-index $=32$, ISI Web of Science). 